\title{
Photocuring and thermal post-curing of a cycloaliphatic epoxide resin with a trithiol and a vinyl epoxy compound
}

\section{J. M. Morancho, X. Fernández-Francos, X. Ramis, J. M. Salla \& À. Serra}

Journal of Thermal Analysis and Calorimetry

An International Forum for Thermal Studies

ISSN 1388-6150

J Therm Anal Calorim

DOI 10.1007/s10973-015-4535-y

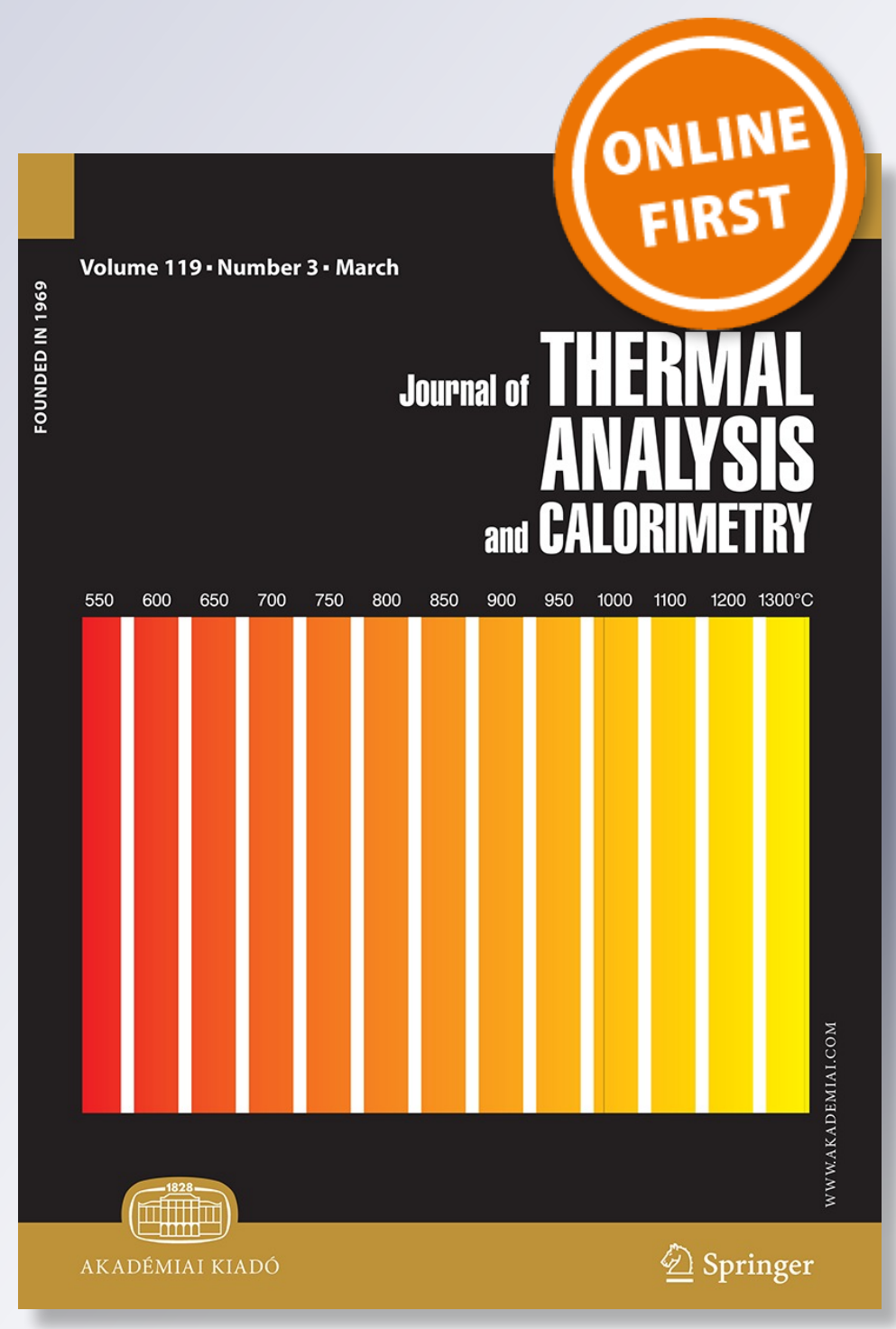

望 Springer 
Your article is protected by copyright and all rights are held exclusively by Akadémiai Kiadó, Budapest, Hungary. This e-offprint is for personal use only and shall not be selfarchived in electronic repositories. If you wish to self-archive your article, please use the accepted manuscript version for posting on your own website. You may further deposit the accepted manuscript version in any repository, provided it is only made publicly available 12 months after official publication or later and provided acknowledgement is given to the original source of publication and a link is inserted to the published article on Springer's website. The link must be accompanied by the following text: "The final publication is available at link.springer.com". 


\title{
Photocuring and thermal post-curing of a cycloaliphatic epoxide resin with a trithiol and a vinyl epoxy compound
}

\author{
J. M. Morancho • X. Fernández-Francos • \\ X. Ramis • J. M. Salla • À. Serra
}

Received: 16 September 2014/ Accepted: 3 February 2015

(C) Akadémiai Kiadó, Budapest, Hungary 2015

\begin{abstract}
In this work, the influence of trimethylolpropane tris-(3-mercaptopropionate) and a vinyl epoxy compound (4-vinyl-1-cyclohexene 1,2-epoxide) over the photocuring and subsequent thermal curing of an epoxy resin (CYRACURE UVR-6105) is studied. The photoinitiator used is CYRACURE UVI-6976. The techniques used in this study have been DSC (differential scanning calorimetry) and FTIR (Fourier transform infrared spectroscopy). In the isothermal photocuring, when the proportion of the modifiers are $5 \%$ or greater, the photopolymerization of the epoxy resin is stopped by the thiol-ene reaction of both modifiers, due to the formation of alkyl sulfonium salts, decreasing the maximum degree of conversion of the process. After the photocuring process, the different systems studied have been post-cured thermally and the activation energy of this process has been determined using a differential isoconversional method. When the epoxy resin is neat or only it has been added $2.5 \%$ of the modifiers, at the beginning of the post-curing the activation energy decreases, but when the proportion of the modifiers is $5 \%$ or greater, the activation energy always increases.
\end{abstract}

J. M. Morancho $(\bowtie) \cdot$ X. Ramis · J. M. Salla

Thermodynamics Laboratory, Heat Engines Department, ETSEIB, Universitat Politècnica de Catalunya, Av. Diagonal 647, 08028 Barcelona, Spain

e-mail: morancho@mmt.upc.edu

X. Fernández-Francos

Centre Tecnològic de la Química de Catalunya, C/Marcel·lí

Domingo s/n, 43007 Tarragona, Spain

X. Fernández-Francos · À. Serra

Department of Analytical and Organic Chemistry, Universitat

Rovira i Virgili, C/Marcel-lí Domingo s/n, 43007 Tarragona, Spain
Keywords Epoxy networks - Thiol-ene - Photocuring · Thermal curing $\cdot$ Kinetics

\section{Introduction}

One of the most important applications of the epoxy resins is their use as adhesives [1-3]. However, one of the problems of this application is that as soon as the epoxy adhesive is applied, the components have to be assembled and cured immediately, creating expensive production bottlenecks. To reduce this problem, it can be used a B-stage (or dual-cure) adhesive, where the curing process has two steps [4]. In this way, the system can be held for a period of time before the final curing stage, without sacrificing performance and eliminating bottlenecks. There are examples of B-staging or dual-curing of formulations making use of photocuring technology [5-7]. In a first step, the resin is applied onto one substrate and UV-irradiated, but without being completely cured, and in the second one, after assembling the components, the resin is completely cured by a thermal post-curing.

The concept of click reactions was introduced in 2001 by Kolb et al. [8], who focus attention on highly selective reactions that do not yield side products and that give heteroatom-linked molecular systems with high efficiency under a variety of mild conditions. There are several applications of the click reactions, like high performance of protective polymer networks, protective coatings, films and optical, biomedical and bioorganic fields [9]. Thiol-ene reaction (see Scheme 1) is a kind of versatile click reaction widely used for synthetic purposes but also in thermosetting formulations having applications such as dental restorative materials [10] or reinforced composites with structural applications [11]. 


$$
\mathrm{R}-\mathrm{SH}+\mathrm{H}_{2} \mathrm{C}=\mathrm{CH}-\mathrm{R}^{\prime} \longrightarrow \mathrm{R}-\mathrm{S}-\mathrm{CH}_{2}-\mathrm{CH}_{2}-\mathrm{R}^{\prime}
$$

Scheme 1 Reaction between a thiol group and a double bond

Another application of thiol-ene reaction is in the design of UV-curable B-stage adhesives, in combination with the cationic photopolymerization of epoxides [12, 13]. Upon irradiation, the thiol-ene condensation leads to the formation of sulfide bonds (see Scheme 1) and to the photolysis of the photoinitiator, leading to the formation of a superacid capable of initiating the epoxy homopolymerization reactions (see Scheme 2). The thiol-ene polymerization can take place with added photoinitiator [14] or without [15]. However, it is acknowledged that the radicals formed during photolysis of the cationic photoinitiator [16] can also accelerate the thiol-ene condensation. The sulfide bonds formed are nucleophilic enough to react with the oxonium cations that propagate the epoxy homopolymerization (see Scheme 3), leading to the formation of stable alkylsulfonium salts, slowing down or even stopping epoxy homopolymerization $[12,13,17,18]$. Alkylsulfonium salts can act as latent thermal cationic initiators, resuming dark epoxy polymerization upon post-curing at a higher temperature, thus allowing the material to reach complete conversion [17]. Recently, this concept was applied in the cationic photocuring of epoxides using hyperbranched polymeric modifiers [17, 18]. Some authors also describe that thiol compounds can react with propagating oxonium cations leading to species containing sulfide bonds [13] having the same effect as those coming from the thiol-ene reaction.

In this work, the influence of a thiol-ene reaction over the photocuring and subsequent thermal curing of an epoxy resin is studied. The techniques used have been DSC (differential scanning calorimetry) and FTIR (infrared spectroscopy by Fourier transform). Using a differential isoconversional method, the kinetics of the thermal post-curing has been analyzed.

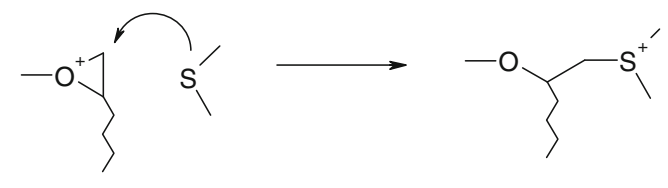

Scheme 3 Blockage of the homopolymerization of the epoxy resin by the formation of alkylsulfonium salts

\section{Experimental}

\section{Materials}

The epoxy resin used is 3,4-epoxycyclohexylmethyl- $3^{\prime}, 4^{\prime}$ epoxycyclohexanecarboxylate (CYRACURE UV-6105, The Dow Chemical Company), with an epoxy equivalent of $130 \mathrm{~g} \mathrm{ee}^{-1}$. The thiol used is trimethylolpropane tris-(3mercaptopropionate) (Aldrich), from now on, trithiol. The vinyl epoxy compound used is 4-vinyl-1-cyclohexene-1,2epoxide (Aldrich), from now on, vinyl compound. Scheme 4 shows the formulae of these compounds. Triarylsulfonium hexafluoroantimonate (TAS-Sb) $(50 \%$ in propylene carbonate, The Dow Chemical Company) has been used as cationic photoinitiator.

\section{Preparation of curing systems}

The trithiol $(1 \mathrm{~mol})$ and the vinyl compound $(3 \mathrm{~mol})$ were mixed in stoichiometric proportions, and after that, the epoxy resin was added until the total proportion of the trithiol and the vinyl compound was 2.5 , 5 or $10 \%$. Immediately, the photoinitiator was added so that its proportion was 2 phr (because the concentration of photoinitiator was $50 \%$ in the photoinitiator solution, $2 \mathrm{phr}$ of this solution was needed for a concentration of 1 phr of photonitiator in the reactive mixture). The resulting mixture was stirred and kept in the dark at $-18{ }^{\circ} \mathrm{C}$ to prevent photoactivation and polymerization.
Scheme 2 a Initiation of the epoxy homopolymerization with the proton generated by the photolysis of the photoinitiator and propagation by the b secondary oxonium ion and c tertiary oxonium ion

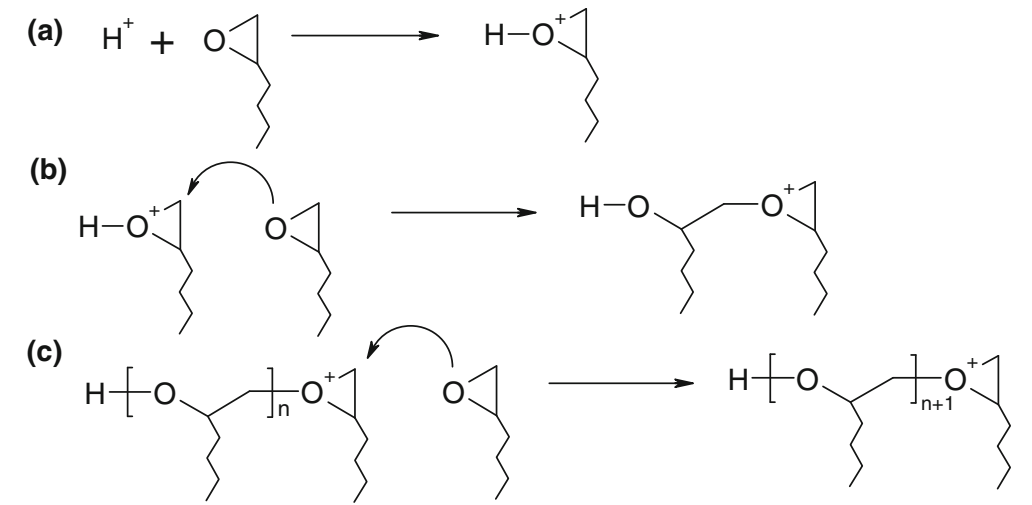




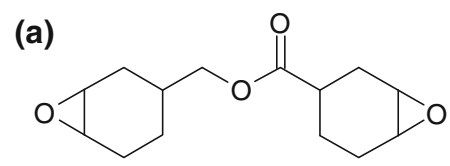

(b)

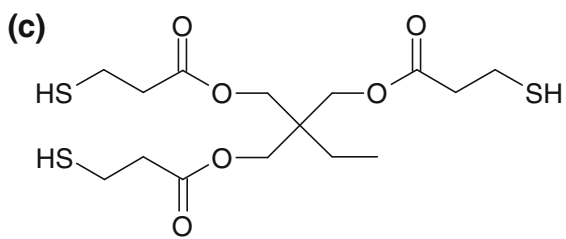

Scheme 4 Chemical structures of a 3,4-epoxycyclohexylmethyl$3^{\prime}, 4^{\prime}$-epoxycyclohexanecarboxylate, b 4-vinyl-1-cyclohexene-1,2-epoxide and $\mathbf{c}$ trimethylolpropane tris-(3-mercaptopropionate)

\section{Photocuring}

Samples of the different systems were photocured at different temperatures, with a Mettler DSC-821e calorimeter appropriately modified with a Hamamatsu Lightningcure LC5 (Hg-Xe lamp) with two beams, one for the sample side and the other for the reference side. Samples of ca $5 \mathrm{mg}$ were cured in open aluminum pans in a nitrogen atmosphere. Two scans were performed on each sample to subtract the thermal effect of UV irradiation from the photocuring experiment, and finally 4 more minutes without UV light. The light intensity used was $21 \mathrm{~mW} \mathrm{~cm}^{-2}$ and was calculated by irradiation of graphite-filled pans on only the sample side.

The process of the photocuring was also analyzed by FTIR, using a Bruker Vertex 70 FTIR spectrometer equipped with an attenuated total reflection (ATR) accessory (Golden GateTM, Specac Ltd.) which is temperature controlled (heated single-reflection diamond ATR crystal) and equipped with a liquid nitrogen-cooled mercury-cadmium-telluride (MCT) detector. Spectra were collected at $35^{\circ} \mathrm{C}$ in absorbance mode with resolution of $4 \mathrm{~cm}^{-1}$ in the wavelength range from 600 to $400 \mathrm{~cm}^{-1}$, and 20 scans were averaged for each spectrum. A Hamamatsu Lightningcure LC5 ( $\mathrm{Hg}-\mathrm{Xe}$ lamp) with one beam conveniently adapted to the ATR accessory was used to irradiate the samples. A wire-wound rod was used to set a sample thickness of $50 \mu \mathrm{m}$. The OPUS ${ }^{\mathrm{TM}}$ software was used for the analysis of the spectra.

Thermal post-curing

Samples of the epoxy resin modified with different proportions of the trithiol and the vinyl compound have been photocured at room temperature for $30 \mathrm{~min}$ in a UV oven (Vilbert Lourmat Bio-Link Crosslinker) equipped with 6 lamps of $8 \mathrm{~W}$ each emitting $365 \mathrm{~nm}$ wavelength UV radiation. After that, they have been post-cured in a Mettler DSC-822e calorimeter from 0 to $300{ }^{\circ} \mathrm{C}$ at different heating rates $\left(2.5,5,7.5,10\right.$ and $\left.15^{\circ} \mathrm{C} \min ^{-1}\right)$.

The glass transition temperature $\left(T_{\mathrm{g}}\right)$ of the fully cured samples has been determined by modulated DSC in a Mettler DSC-822e calorimeter, from 50 to $250{ }^{\circ} \mathrm{C}$ at an underlying heating rate of $2{ }^{\circ} \mathrm{C} \mathrm{min}{ }^{-1}$, an amplitude of $0.5{ }^{\circ} \mathrm{C}$ and a modulation period of $1 \mathrm{~min}$. The value of the $T_{\mathrm{g}}$ has been taken as the middle point of the heat capacity step in the reversing heat flow curve.

\section{Theory}

\section{Photocuring}

In the photocuring process analyzed by DSC, the degree of conversion $(\alpha)$ was calculated as:

$\alpha=\frac{\int_{0}^{t} \frac{\mathrm{d} h}{\mathrm{~d} t} \cdot \mathrm{d} t}{\Delta h_{\text {calc }}}$

where $\mathrm{d} h / \mathrm{d} t$ is the heat flow released by the sample during the photocuring, integrated up to a time $t$ and $\Delta h_{\text {calc }}$ has been estimated considering a heat of reaction of $80 \mathrm{~kJ}$ ee for the polymerization of the epoxy resin a heat of reaction of $43.9 \mathrm{~kJ} \mathrm{~mol}^{-1}$ for the addition of the thiol group across the double bond of the vinyl compound [9].

In the photocuring studied by FTIR, $\alpha_{\text {ep }}$ represents the conversion of the epoxy groups. This conversion has been found as:

$\alpha_{\mathrm{ep}}=1-\frac{A^{\prime}}{A_{\mathrm{o}}^{\prime}}$

where $A^{\prime}$ is the absorbance of the epoxy (740 and $790 \mathrm{~cm}^{-1}$ ) normalized with that of the ester group of the epoxy resin and the trithiol $\left(1730 \mathrm{~cm}^{-1}\right)$ and $A_{\mathrm{o}}^{\prime}$ the value of this absorbance at time 0 . As the proportion of the epoxy resin in the samples is great ( $90 \%$ or more), this degree of conversion is very similar to calculated one by Eq. (1).

\section{Thermal post-curing}

In the thermal post-curing studied by DSC, the relative degree of conversion $\left(\alpha^{\prime}\right)$ is defined as:

$$
\alpha^{\prime}=\frac{\int_{T_{0}}^{T} \frac{\mathrm{d} h}{\mathrm{~d} t} \cdot \frac{1}{\beta} \cdot \mathrm{d} T}{\Delta h_{\mathrm{dyn}}}
$$

where $\beta$ is the heating rate $(\mathrm{d} T / \mathrm{d} t), \mathrm{d} h / \mathrm{d} t$ is the heat flow released by the sample during the dynamic post-curing, integrated from the beginning of the process at a 
temperature $T_{0}$ up to a temperature $T$ and $\Delta h_{\text {dyn }}$ is the total reaction heat released during the thermal post-curing. $\alpha^{\prime}$ is not the same than the degree of conversion of the photocuring, because at the beginning of the thermal postcuring the system has already been partially reacted: $\alpha^{\prime}$ is zero but $\alpha$ has a determined value different of zero.

The kinetics of the thermal post-curing has been analyzed by means of a differential isoconversional method, using the Friedman equation [19]:

$\ln \left(\frac{\mathrm{d} \alpha^{\prime}}{\mathrm{d} t}\right)_{\alpha^{\prime}}=\ln \left[f\left(\alpha^{\prime}\right) A_{\alpha^{\prime}}\right]-\frac{E_{\alpha^{\prime}}}{\mathrm{RT}_{\alpha^{\prime}}}$

where $R$ is the gas constant and at a determined value of relative degree of conversion, $f\left(\alpha^{\prime}\right)$ is a function of $\alpha^{\prime}, A_{\alpha^{\prime}}$ is the frequency factor, $E_{\alpha^{\prime}}$ is the activation energy and $T_{\alpha^{\prime}}$ is the temperature attained. Representing $\ln \left(\mathrm{d} \alpha^{\prime} \mathrm{d} t\right)_{\alpha^{\prime}}$ versus the reciprocal of the temperature, the activation energy can be found from the slope of the representation for different values of the relative degree of conversion.

\section{Results and discussion}

\section{Photocuring}

Figures 1 and 2 show the evolution of the photocuring process of the epoxy resin modified with different proportions of the trithiol and the vinyl compound. Curves in Fig. 1 have been obtained at $40{ }^{\circ} \mathrm{C}$ using DSC. Figure 2 has been obtained at the same temperature using FTIR. It can be seen that the neat epoxy resin and the modified one with $2.5 \%$ of the trithiol and the vinyl compound have a similar behavior. However, if the proportion of the modifiers added is $5 \%$ or greater, the reaction of the epoxy resin is stopped ant the degree of conversion attained at the final of the process decreases, due to in situ

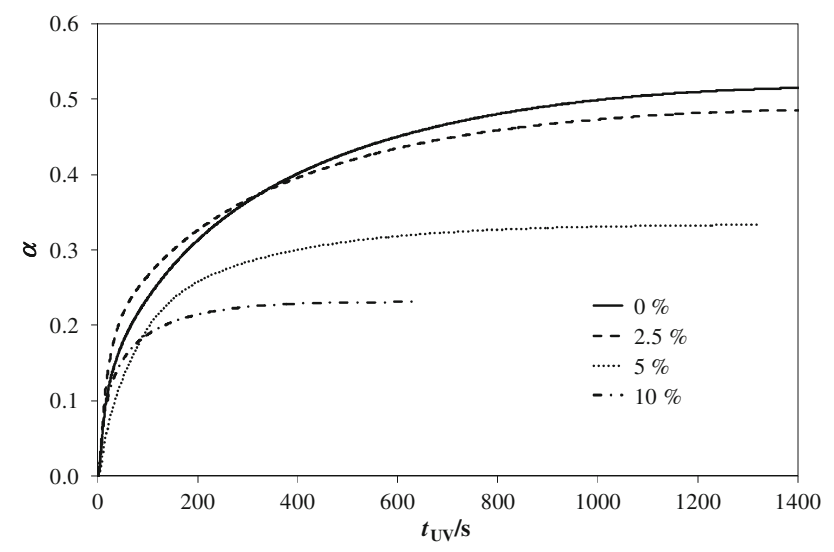

Fig. 1 Photocuring of the epoxy resin using a DSC at $40{ }^{\circ} \mathrm{C}$, with different proportions of trithiol and vinyl compound

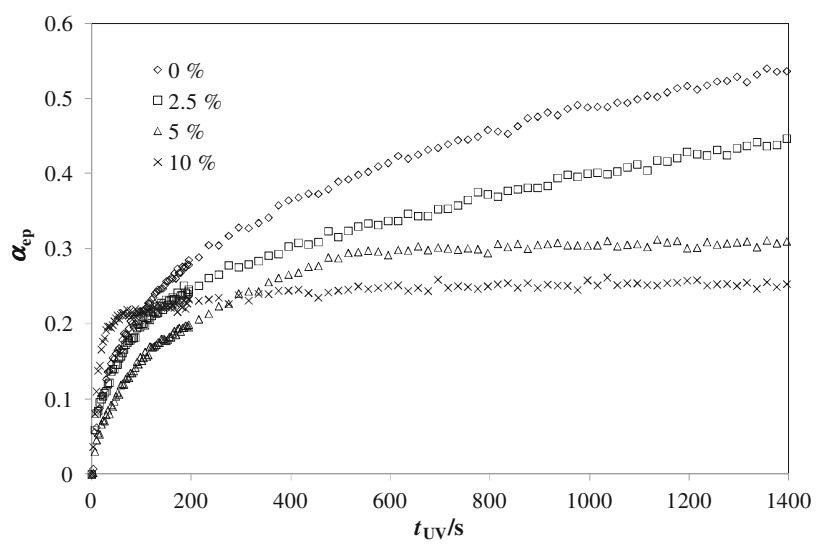

Fig. 2 Photocuring of the epoxy resin using a FTIR at $40{ }^{\circ} \mathrm{C}$, with different proportions of trithiol and vinyl compound

formation of alkyl sulfonium salts, as described in the introduction. The thiol-ene reaction is very fast, completely finished in $5 \mathrm{~s}$, as seen from the monitoring of the absorbance of the vinyl group $\left(1640 \mathrm{~cm}^{-1}\right)$. The photocured samples of the neat formulation and that containing $2.5 \%$ of the trithiol and the vinyl compound were rigid and tack-free, indicating that vitrification had taken place. In the contrary, samples containing 5 and $10 \%$ of the trithiol and the vinyl compound were soft and sticky, indicating that the reaction had stopped before vitrification could take place. It can be seen in Table 1 that in the modified systems the number of vinyl and thiol equivalents are always greater than in the photoinitiator ones. Then, the formation of alkyl sulfonium salts can be facilitated and the homopolymerization reaction stopped at lower temperatures, although in the system with $2.5 \%$ of the trithiol and the vinyl compound, there is not enough quantity of the modifiers to stop completely this reaction during the photopolymerization process before vitrification takes place.

Table 2 shows the maximum degrees of conversion of the photocuring by DSC of the epoxy resin at different temperatures with different proportions of the trithiol and the vinyl compound. This degree of conversion increases with temperature, as commonly observed for other photocuring systems $[6,20-23]$ due to vitrification occurring at higher degrees of conversion when the photocuring temperature increases [24]. However, it is shown that the effect is very small when the proportion of thiol-ene modifiers is $5 \%$ or greater, showing that, even if the temperature increases, the stability of the alkylsulfonium salts formed in the photocuring stage is sufficiently high to prevent epoxy homopolymerization from taking place at these temperatures, as reported previously [17]. When the proportion of trithiol and vinyl compound is only $2.5 \%$, the photocuring of the epoxy resin is hardly affected and the results are very similar to the neat formulation. 
Table 1 Composition of the different formulations in equivalents of epoxy, vinyl compound, thiol and photoinitiator for the different systems studied, calculated for $100 \mathrm{~g}$ of sample

\begin{tabular}{llll}
\hline Modifiers/\% $\%$ & $\begin{array}{l}\text { Number of epoxy } \\
\text { equivalents }\end{array}$ & $\begin{array}{l}\text { Number of vinyl compound } \\
\text { and thiol equivalents }\end{array}$ & $\begin{array}{l}\text { Number of TAS-Sb } \\
\text { equivalents }\end{array}$ \\
\hline 0 & 0.769 & 0 & $1.80 \times 10^{-3}$ \\
2.5 & 0.760 & $9.73 \times 10^{-3}$ & $1.80 \times 10^{-3}$ \\
5 & 0.750 & $1.95 \times 10^{-2}$ & $1.80 \times 10^{-3}$ \\
10 & 0.731 & $3.89 \times 10^{-2}$ & $1.80 \times 10^{-3}$ \\
\hline
\end{tabular}

Table 2 Maximum degree of conversion of the photocuring of the epoxy resin using a DSC, with different temperatures and proportions of the modifiers (trithiol and vinyl compound)

\begin{tabular}{lllll}
\hline Modifiers/\% & $30{ }^{\circ} \mathrm{C}$ & $40{ }^{\circ} \mathrm{C}$ & $50{ }^{\circ} \mathrm{C}$ & $60{ }^{\circ} \mathrm{C}$ \\
\hline 0 & 0.39 & 0.52 & 0.60 & 0.63 \\
2.5 & 0.42 & 0.49 & 0.51 & 0.64 \\
5 & 0.32 & 0.33 & 0.39 & 0.46 \\
10 & 0.21 & 0.23 & 0.24 & 0.29 \\
\hline
\end{tabular}

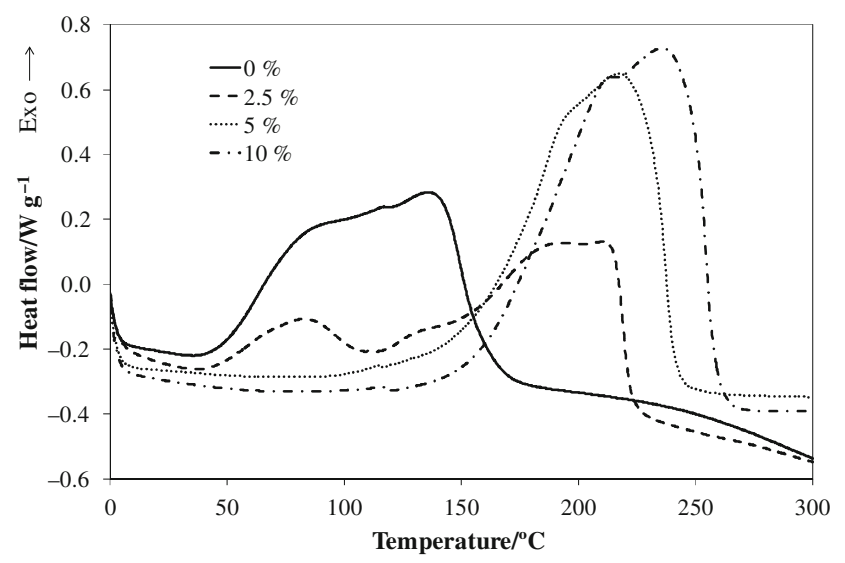

Fig. 3 Heat flow of thermal post-curing of the epoxy resin with different proportions of trithiol and vinyl compound at $10{ }^{\circ} \mathrm{C} \mathrm{min}-1$ after photocuring at room temperature for $30 \mathrm{~min}$

\section{Thermal post-curing}

The thermal post-curing at $10{ }^{\circ} \mathrm{C} \min ^{-1}$ of the epoxy resin modified with different proportions of the trithiol and the vinyl compound are shown in Fig. 3. In the case of the neat epoxy resin, the thermal post-curing resumes immediately after devitrification, but when the proportion of the modifiers is $5 \%$ or greater, this process takes place at higher temperatures because of the latent character of the formed alkyl sulfonium salts [17]. When the proportions of modifiers is $2.5 \%$, a fraction of the active species resume the cure after vitrification, but then curing is slowed down again by the formation and presence of alkyl sulfonium salts.
Table 3 Total reaction heat released (in $\mathrm{J} \mathrm{g}^{-1}$ ) during the thermal post-curing at different proportions of modifiers and heating rates

\begin{tabular}{llllll}
\hline Modifiers/\% & \multicolumn{3}{l}{$\beta /{ }^{\circ} \mathrm{C} \mathrm{min}^{-1}$} & & \\
\cline { 2 - 6 } & 2.5 & 5 & 7.5 & 10 & 15 \\
\hline 0 & 217 & 245 & 255 & 267 & 286 \\
2.5 & 269 & 280 & 288 & 295 & 309 \\
5 & 374 & 378 & 373 & 370 & 372 \\
10 & 446 & 458 & 455 & 453 & 458 \\
\hline
\end{tabular}

Table 3 shows the values of the total reaction heat released during the thermal post-curing at different proportions of modifiers and heating rates. The systems with 5 or $10 \%$ have the highest post-curing heat because of the decrease in the conversion of the photocuring when the modifiers proportion is increased, as it is shown in Table 2 .

Figure 4 shows the thermal post-curing process of the epoxy resin modified with $10 \%$ of trithiol and vinyl compound for different heating rates. As the heating rate increases, the corresponding scan is displaced toward higher temperatures and the height of the peak also increases, as commonly observed. The shape of the curves at the different heating rates is similar, thus validating the iso-conversional procedure used for the obtainment of kinetic parameters.

Figure 5 shows the values of the activation energy found using Eq. (4) for the neat epoxy resin. At the beginning of the thermal post-curing, the activation energy is around 250-300 $\mathrm{kJ} \mathrm{mol}^{-1}$, which is consistent with the devitrification occurring in the post-curing upon heating [24]. Different authors have reported activation energies upon vitrification of about $300 \mathrm{~kJ} \mathrm{~mol}^{-1}[25,26]$. As the curing advances, it decreases and above $\alpha^{\prime}=0.7$ it increases slightly up to ca. $160 \mathrm{~kJ} \mathrm{~mol}^{-1}$.

In Fig. 6 the activation energy found from Eq. (4) is represented for the systems with 5 and $10 \%$ of the modifiers. This magnitude always increases and has similar values for both systems. This trend is consistent with the fact that samples had not vitrified during the photocuring, as described above. The values of the activation energy are very similar to those obtained at the end of the post-curing of the neat formulation, when this material is devitrified. 


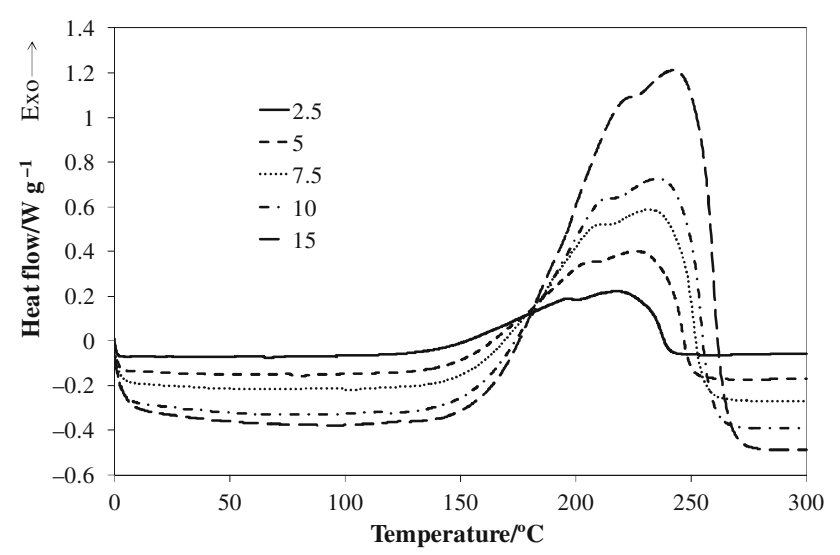

Fig. 4 Thermal post-curing of the epoxy resin modified with $10 \%$ of trithiol and vinyl compound at different heating rates after photocuring at room temperature for $30 \mathrm{~min}$

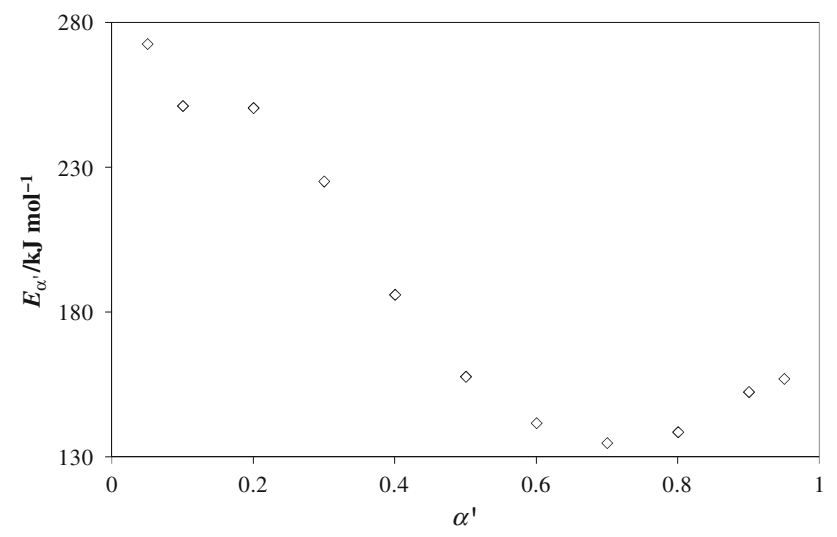

Fig. 5 Activation energy versus degree of conversion of the thermal post-curing of the neat epoxy resin

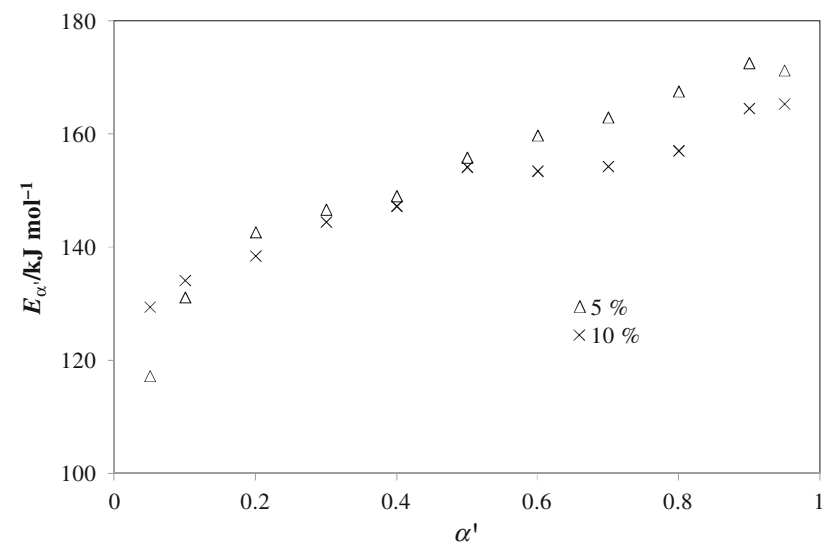

Fig. 6 Activation energy versus degree of conversion of the thermal post-curing of the epoxy resin modified with 5 and $10 \%$ of trithiol and vinyl compound

In the system with $2.5 \%$ of the modifiers, the different peaks have been separated using the program 'Peak.Fit' provided by Jandel Scientific Software and the function
'Gauss Amp'. However, only the kinetics of the first peak has been analyzed because the rest of the peaks are not well separated. Using Eq. (4), the activation energy has also been found, and the results obtained have been represented in Fig. 7. This activation energy always decreases due to the devitrification. This behavior is similar to the corresponding to epoxy resin before $\alpha^{\prime}=0.7$, because the first peak of the system with $2.5 \%$ of the modifiers corresponds with the thermal post-curing of the neat epoxy resin before this degree of conversion as it is shown in Fig. 3.

From the above results, it follows that only formulations containing $5 \%$ of trithiol and vinyl compound or above can be safely used as dual-curable formulations. For the formulation containing only $2.5 \%$ of the trithiol and vinyl compound, the epoxy polymerization cannot be stopped during the photopolymerization process before vitrification takes place, and the post-curing process cannot be controlled as efficiently.

Table 4 shows the values of the glass transition temperature of the fully cured samples. Adding the modifiers, the value of this magnitude decreases, but at a proportion of these modifiers greater than $5 \%$, the $T_{\mathrm{g}}$ begins to increase. In any case, the modified systems have always a smaller $T_{\mathrm{g}}$ than the neat epoxy resin, because of the loosening of the network structure caused by the presence of the flexible trithiol.

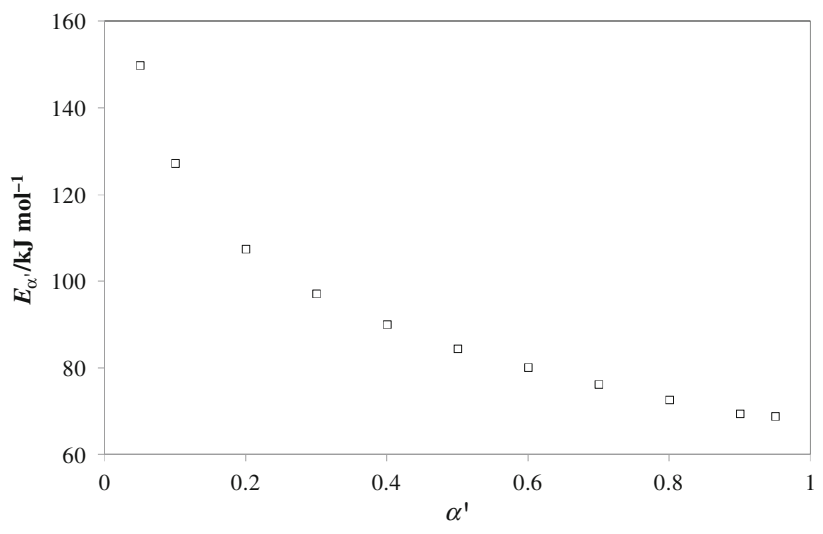

Fig. 7 Activation energy versus degree of conversion of the thermal post-curing of the epoxy resin modified with $2.5 \%$ of trithiol and vinyl compound

Table 4 Glass transition temperature of the neat epoxy resin and of the epoxy resin with different proportions of the modifiers completely cured

\begin{tabular}{lc}
\hline Modifiers $/ \%$ & $T_{\mathrm{g}} /{ }^{\circ} \mathrm{C}$ \\
\hline 0 & 144 \\
2.5 & 138 \\
5 & 137 \\
10 & 139 \\
\hline
\end{tabular}




\section{Conclusions}

In formulations containing epoxy resin, the trithiol and the vinyl compound, the occurrence of thiol-ene polymerization in the early stages of the photocuring leads to the formation of stable alkyl sulfonium salts, slowing down the cationic homopolymerization and eventually stopping it. Alkyl sulfonium salts formed in situ act as latent thermal cationic initiators for the homopolymerization of epoxides in a thermal post-curing stage at a higher temperature, leading to complete conversion.

A beneficial effect is that epoxy formulations with thiol and vinyl groups can be used in complex processes involving a series of curing steps in different places in a controlled manner. One of the possible applications is its use as B-stage (dual) adhesive. To obtain a dual-cure system, it is necessary to add a $5 \%$ or more of the modifiers. The degree of conversion at the end of the photocuring can be modulated by the proportion of the modifiers.

Acknowledgements The authors would like to thank MICINN (Ministerio de Ciencia e Innovación) and FEDER (Fondo Europeo de Desarrollo Regional) (MAT2011-27039-C03-01 and MAT201127039-C03-02 and contract JCI-2010-06187) and to the Comissionat per a Universitats i Recerca del DIUE de la Generalitat de Catalunya (2014-SGR-67).

\section{References}

1. Riew CK, Siebert AR, Smith RW, Fernando M, Kinloch AJ. Toughened epoxy resins: performed particles as tougheners for adhesives and matrices. In: Riew CK, Kinloch AJ, editors. Toughened plastics II novel approaches in science and engineering. Advances in chemical series, vol. 252. Washington: American Chemical Society; 1996. p. 33-44.

2. Saiki N, Yamazaki O, Ebe K. UV/heat dual-curable adhesive tapes for fabricating stacked packages of semiconductors. J Appl Polym Sci. 2008;108:1178-83.

3. Kang B-U. Interfacial fracture behavior of epoxy adhesives for electronic components. J Korea Acad Ind Cooper Soc. 2011;12:1479-87.

4. Tech Tip 20. B-stage epoxy. In: Epo-tek tech tips. Epoxy technology. 2012. http://www.epotek.com/site/files/Techtips/pdfs/ tip20.pdf. Accessed 21 July 2014.

5. Studer K, Decker C, Beck E, Schwalm R. Thermal and photochemical curing of isocyanate and acrylate functionalized oligomers. Eur Polym J. 2005;41:157-67.

6. Decker C, Masson F, Schwalm R. Dual-curing of waterborne urethane-acrylate coatings by $\mathrm{UV}$ and thermal processing. Macromol Mater Eng. 2003;288:17-28.

7. Kropp M, Behr A. UV B-stage technology provides process \& performance advantages. In: Innovations in IC packaging adhesives. Solid state technology. 2005. http://electroiq.com/blog/ 2005/08/innovations-in-ic-packaging/adhesives/. Accessed 21 July 2014

8. Kolb HC, Finn MG, Sharpless KB. Click chemistry: diverse chemical function from a few good reactions. Angew Chem Int Ed. 2001;40:2004-21.
9. Hoyle CE, Bowman CN. Thiol-ene click chemistry. Angew Chem Int Ed. 2010;49:1540-73.

10. Cramer NB, Couch CL, Schreck KM, Carioscia JA, Boulden JE, Stansbury JW, Bowman CN. Investigation of thiol-ene and thiolene-methacrylate based resins as dental restorative materials. Dent Mater. 2010;26:21-8.

11. Trey SM, Gamstedt EK, Mäder E, Jönsson S, Johansson M. Glass fiber reinforced high glass transition temperature thiol-ene networks. Compos Part A Appl Sci Manuf. 2011;42:1800-8.

12. Sangermano M, Cerrone M, Colucci G, Roppolo I, Acosta Ortiz R. Preparation and characterization of hybrid thiol-ene/epoxy UV-thermal dual-cured systems. Polym Int. 2010;59:1046-51.

13. Acosta Ortiz R, Puente Urbina BA, Cabello Valdez LV, Berlanga Duarte L, Guerrero Santos R, García Valdez AE, Soucek MD. Effect of introducing a cationic system into a thiol-ene photopolymerizable formulation. J Polym Sci, Part A: Polym Chem. 2007;45:4829-43.

14. Cramer NB, Davies T, O'Brien AK, Bowman CN. Mechanism and modeling of a thiol-ene photopolymerization. Macromolecules. 2003;36:4631-6.

15. Cramer NB, Scott JP, Bowman CN. Photopolymerizations of thiol-ene polymers without photoinitiators. Macromolecules. 2002;35:5361-5.

16. Crivello JV. The discovery and development of onium salt cationic photoinitiators. J Polym Sci, Part A: Polym Chem. 1999;37:4241-54.

17. Flores J, Tomuta AM, Fernández-Francos X, Ramis X, Sangermano M, Serra A. A new two-stage curing system: thiol-ene/epoxy homopolymerization using an allyl terminated hyperbranched polyester as reactive modifier. Polymer. 2013;54:5473-81.

18. Foix D, Ramis X, Serra A, Sangermano M. UV generation of a multifunctional hyperbranched thermal crosslinker to cure epoxy resins. Polymer. 2011;52:3269-76.

19. Vyazovkin S, Burnham AK, Criado JM, Pérez-Maqueda LA, Popescu C, Sbirrazzuoli N. ICTAC Kinetics Committee recommendations for performing kinetic computations on thermal analysis data. Therm Acta. 2011;520:1-19.

20. Morancho JM, Cadenato A, Ramis X, Morell M, FernándezFrancos X, Salla JM, Serra A. Thermal curing and photocuring of a DGEBA modified with multiarm star poly(glycidol)- $b$-poly( $\varepsilon$ caprolactone) polymers of different arm lengths. J Therm Anal Calorim. 2013;114:409-16.

21. Voytekunas VY, Ng FL, Abadie MJM. Kinetics study of the UVinitiated cationic polymerization of cycloaliphatic diepoxide resins. Eur Polym J. 2008;44:3640-9.

22. Lovell LG, Newman SM, Bowman CN. The effects of light intensity, temperature and comonomer composition on the polymerization behavior of dimethacrylate dental resins. J Dent Res. 1999;78:1469-76.

23. Lecamp L, Youssef B, Bunel C, Lebaudy P. Photoinitiated polymerization of a dimethacrylate oligomer: 2. Kinetic studies. Polymer. 1999;40:1403-9.

24. Scott TF, Cook WD, Forsythe JS. Photo-DSC cure kinetics of vinyl ester resins. I. Influence of temperature. Polymer. 2002;43:5839-45.

25. Van Assche G, Swier S, Van Mele B. Modeling and experimental verification of the kinetics of reacting polymer systems. Therm Acta. 2002;388:327-41.

26. Santiago D, Fernández-Francos X, Ramis X, Salla JM, Sangermano M. Comparative curing kinetics and thermal-mechanical properties of DGEBA thermosets cured with a hyperbranched poly(ethyleneimine) and an aliphatic triamine. Therm Acta. 2011;526:9-21. 